\title{
Türkiye muz yetiştiriciliğinde gelecek vadeden yeni bir üretim alanı: Arsuz, Hatay
}

\section{A promising new production area in Turkey for banana cultivation: Arsuz, Hatay}

\author{
Atila Aytekin POLAT ${ }^{*}$ iD \\ ${ }^{1}$ Hatay Mustafa Kemal Üniversitesi Ziraat Fakültesi Bahçe Bitkileri Bölümü, Hatay, Turkiye
}

\section{To cite this article:}

Polat, A.A. (2019). Türkiye muz yetiştiriciliğinde gelecek vadeden yeni bir üretim alanı: Arsuz, Hatay. Harran Tarım ve Gıda Bilimleri Dergisi, 23(4):400409.

DOI: $10.29050 /$ harranziraat.547934

Address for Correspondence: Atila Aytekin POLAT e-mail:

aapolat@mku.edu.tr

Received Date:

01.04.2019

Accepted Date:

21.06.2019

(c) Copyright 2018 by Harran University Faculty of Agriculture. Available on-line at www.dergipark.gov.tr/harranziraat
Öz

Çalışma, ülkemiz muz yetiştiriciliğinde ümitvar yeni bir üretim alanı olan Hatay'ın Arsuz ilçesindeki üretici seralarında yapılmıştır. Seçilen seralarda, 'Grand Nain' muz çeşidi yetiştirilmekte olup, araştırmada bu çeşit kullanıımıştır. Çalışmada, bitki gövde çevresi, hevenk özellikleri(hevenk ağırlı̆̆ı, hevenk uzunluğu, hevenk çevresi, hevenkteki tarak sayısı, tarak ağırlığı, hevenkteki toplam parmak sayısı vb.) ile meyve kalite özellikleri(parmakların eni ve boyu, parmak ağırlığı, kabuk ağırlığı ve kabuk kalınlığı, meyve eti oranı, suda çözünebilir toplam kuru madde (SÇKM) ve titre edilebilir asit miktarı) ve verim parametreleri (dekara verim ve birim gövde kesit alanına düşen verim) değerlendirilmiştir. Sonuç olarak, Arsuz'da 1 dekar muz serasından 5112-7802 kg ürün alındığı belirlenmiştir. Birim gövde kesit alanına düşen verim $65.35-100.87 \mathrm{gcm}^{-2}$ olarak ölçülmüştür. Çalışmada, bitki gövde çevresi 65.0-95.0 cm; hevenk ağırlığı 30.8-47.0 kg; hevenk çevresi $118.2-129.0 \mathrm{~cm}$ ve hevenk uzunluğu 90.4$113.8 \mathrm{~cm}$ olarak belirlenmiştir. Tarak sayısı 12.4-13.8 adet, tarak ağırlığı 1286.36-1481.96 g, parmak sayısı 198.6-289.6 adet olarak tespit edilmiştir. Parmak en ve boy değerleri ile parmak ağırlıkları sırasıyla $39.68-40.51 \mathrm{~mm}$ ve $21.43-26.42 \mathrm{~cm}$ ile $126.16-148.02 \mathrm{~g}$ arasında ölçülmüştür. Araştırmamızda, meyve eti oranı \% 67.68-69.47, SÇKM oranı \% 16.64-18.48 arasında belirlenmiştir. Çalışmanın sonuçları, muzun bu bölgede örtü altında başarılı bir şekilde yetiştirilebileceğini ve gelecekte önemli bir üretim alanı olacağını açıkça göstermektedir.

Anahtar Kelimeler:Muz, Hevenk özellikleri, Meyve kalitesi, Verim

\section{ABSTRACT}

The study was conducted under the farmer greenhouses at Arsuz province of Hatay where has being promising new production area. The cultivar of 'Grand Nain' was used which produced in selected greenhouses. In the study, pseudostem circumference, bunch parameters (bunch weight, bunch circumference, bunch length, number of hands per bunch, hand weight, number of fingers per bunch), fruit quality parameters (width and length of fingers, finger weight, peel weight, peel thickness, peel/pulp ratio and soluble solid content and acidity) and yield parameters (yield per decare and yield per pseudostem section) were evaluated. As a result, the yield was determined between 5112 and $7802 \mathrm{~kg} / \mathrm{da}$ at Arsuz, Hatay condition. The yield per pseudostem section area was measured between 65.35 and $100.87 \mathrm{gcm}^{-2}$. The pseudostem circumferencewas determined between 65.0 and $95.0 \mathrm{~cm}$; bunch weight between 30.8 and $47.0 \mathrm{~kg}$; bunch circumference between 118.2 and $129.0 \mathrm{~cm}$; bunch length between 90.4 and $113.8 \mathrm{~cm}$. The number of hands per bunch was 12.4-13.8 pieces, hands weight was 1286.36-1481.96 g; number of fingers per bunch was 198.6-289.6 pieces. The finger circumference, finger length, and finger weight were measured between 39.68 and $40.51 \mathrm{~mm}, 21.43$ and $26.42 \mathrm{~cm}, 126.16-148.02 \mathrm{~g}$, respectively. Total soluble solid contents (TSS) was determined between 16.64 and $18.48 \%$, peel/pulp ratio $67.68 \%$ and $69.47 \%$. The results of the study clearly show that bananas can be successfully grown in protected cultivation in this area and will be an important production area in the future.

Key Words: Banana, Bunch parameters, Fruit quality, Yield 


\section{Giriş}

Muz, dünyada yaygın olarak ekvatorun $20^{\circ}$ kuzey ve güney enlemleri arasında kalan tropik iklim kuşağında yetiştirilmektedir. Ekvatorun $30^{\circ}$ kuzey ve güney enlemleri arasında ise yetiştiricilik subtropik iklim kuşağı olarak adlandırılmaktadır (Stover ve Simmonds, 1987). Subtropik koşullarda muz yetiştiren ülkelere Mısır, İspanya, Güney Afrika, Lübnan, Portekiz, Türkiye, Fas, Ürdün ve İsrail örnek olarak gösterilebilir. Türkiye'de ise muz yetiştiriciliği enlem derecesi olarak subtropik koşulların bile dışında (36 kuzey enlemi) kalmaktadır (Gübbük ve ark., 2010). Buna rağmen, ülkemizde uzun yıllardan bu yana muz açık ve örtü altında ekonomik olarak yetiştirilmektedir. Son yıllarda, özellikle örtü altı yetiştiricilik alanlarında meydana gelen önemli artışlar, ülkemizin muz ihtiyacının önemli bir kısmını kendi öz kaynaklarından karşılayabilecek bir konuma getirmiştir. Bu durum hiç şüphesiz, ithalattan kaynaklanan döviz kaybının önlenmesi açısından bir kazanç olarak düşünülebilir(Balkıç ve ark., 2018).

Tropik ve subtropik koşullarda yetiştirilme şansının olması nedeniyle, muz yaklaşık 100'den fazla ülkede, 10 milyon ha üretim alanı ve 113 milyon tona yakın sofralık ve 35 milyon tonun üzerinde plantain (pişirilerek yenen muzlar) üretimi ile dünyada en yüksek üretim ve ticaret hacmine sahip meyve türlerinin başında yer almaktadır. Ülkemizde ise son yıllarda 7616 ha'a ulaşan üretim alanı ve 498.888 ton üretim miktarı ile ekonomik anlamda üretim potansiyeli yüksek olan bir türdür (TÜiK, 2019). Ülkemiz bu üretim miktarı ile toplam muz tüketimimizin ancak \% 50'den fazlasını karşılamaktadır. Bununla birlikte, son yıllarda örtü altı muz yetiştiricilik alanlarında önemli artışlar kaydedilmiştir. Üretim alanındaki artışlar, aynı hızla artarak devam ederse, birkaç yıl içinde kendi tüketimimizin önemli bir kısmını kendi öz kaynaklarımızdan karşılamamız mümkün gözükmektedir.

Türkiye'de muz yetiştiriciliği ağırlıklı olarak, Akdeniz Bölgesi'nde Mersin ilinin Anamur ve Bozyazı, Antalya ilinde ise Alanya ve Gazipaşa ilçelerinde yapılmaktadır. Bu ilçelerden Anamur ve Bozyazı'da muz yetiştiriciliği genellikle örtü altında, Alanya ve Gazipaşa'da ise açık ve örtü altında yapılmaktadır. Son yıllarda, örtü altı muz üretim alanlarında önemli artışlar olmasında mevcut yetiştiricilik yapılan lokasyonlara yenilerinin dâhil olması etkili olmuştur. Nitekim bu yeni lokasyonlara Antalya'da Manavgat, Serik, Kumluca ve Finike ilçeleri, Mersin'de Erdemli, Hatay'da İskenderun ile Hassa ve Adana'da ise Ceyhan ve Yumurtalık ilçeleri örnek olarak gösterilebilir(Güven ve Gübbük, 2018).

Ülkemizde açıkta yetiştiricilikte yaygın olarak Dwarf Cavendish çeşidi kullanılırken, örtü altında Grand Nain çeşidi yetiştirilmektedir. Ayrıca Dwarf Cavendish ve Grand Nain çeşitlerinin yanı sıra örtü altında halk arasında Azman ve Şimşek olarak adlandırılan muz tipleri de kullanılmaktadır.

$\mathrm{Bu}$ çalışmada temel amaç; yeni bir üretim bölgesi olarak tanımlanabilecek Hatay'ın Arsuz ilçesindeki plastik seralarda yapılan muz yetiştiriciliğinin verim ve kalite kriterleri bakımından değerlendirilmesidir.

\section{Materyal ve Yöntem}

\section{Materyal}

Araştırma, 2015 yılı yetiştiricilik döneminde, Hatay ilinin Arsuz ilçesindeki A tipi çatılı plastik seralarda yetiştirilen 'Grand Nain' muz çeşidi üzerinde yürütülmüştür. Çalışmada yeni bir üretim alanı olarak tanımlanabilecek Hatay ilinin Arsuz ilçesine bağlı Üçgüllük beldesinde farklı lokasyonlardaki 5 üretici serası kullanılmıştır.

Denemenin yapıldığı Arsuz ilçesinin rakımı 3 metre olup, Akdeniz iklimi görülmektedir. Yazları sıcak ve kurak, kışları ılık ve yağışı geçmektedir. Temmuz ayı 8 mm yağışla yılın en kurak, Ocak ayı $152 \mathrm{~mm}$ yağışla yııın en fazla yağış alan ayıdır. Ağustos ayı $27.7^{\circ} \mathrm{C}$ ile yılın en sıcak, Ocak ayı 10.3 $C$ ile yılın en soğuk ayıdır. Yılın en kurak ve en yağışlı ayları arasındaki yağış miktarı farkı 144 mm'dir. Yıl boyunca ortalama sıcaklık 17.4 C civarında seyretmektedir. Denemenin yürütüldüğü yörenin iklim verileri Çizelge 1 'de verilmiştir.

Denemenin yürütüldüğü seraların teknik özellikleri, yetiştirme koşulları, bakım koşulları, vb. özelliklere ilişkin bilgiler aşağıda özetlenmiştir. 
Çizelge 1. Denemenin yürütüldüğü Arsuz ilçesinin iklim verileri

Table 1. The climate data of the Arsuz district where the trial was conducted

\begin{tabular}{|l|c|c|c|c|}
\hline $\begin{array}{l}\text { Aylar } \\
\text { Months }\end{array}$ & $\begin{array}{c}\text { Ortalama Sıcaklık } \\
\text { Average temperature }\end{array}$ & $\begin{array}{c}\text { Min. Sıcaklık } \\
\text { Min. temperature }\end{array}$ & $\begin{array}{c}\text { Max. Sıcaklık } \\
\text { Max. temperature }\end{array}$ & $\begin{array}{c}\text { Yağış (mm) } \\
\text { Precipitation }\end{array}$ \\
\hline Ocak & 10.3 & 6.5 & 14.2 & 152 \\
\hline Şubat & 11.4 & 7.4 & 15.5 & 119 \\
\hline Mart & 14.0 & 9.6 & 18.4 & 67 \\
\hline Nisan & 17.7 & 13.2 & 22.2 & 51 \\
\hline Mayıs & 21.1 & 17.0 & 25.3 & 24 \\
\hline Haziran & 24.3 & 21.0 & 27.7 & 8 \\
\hline Temmuz & 27.0 & 24.3 & 29.8 & 11 \\
\hline Ağustos & 27.7 & 24.8 & 30.6 & 31 \\
\hline Eylül & 26.0 & 22.0 & 30.1 & 90 \\
\hline Ekim & 21.8 & 16.6 & 27.0 & 99 \\
\hline Kasım & 16.7 & 11.8 & 21.7 & 147 \\
\hline Aralık & 12.2 & 8.2 & 16.3 & \\
\hline
\end{tabular}

Deneme seralarının hiçbirinde ısıtma yapılmamaktadır.Seraların havalandırılması yandan ve üstten olmak üzere manuel yöntemle yapılmaktadır. Tüm seralardaki fide dikimleri eylül ayında yapılmış olup dikimde kullanılan fideler, özel bir firmadan tüplü olarak temin edilmiştir. 4 no'lu sera hariç tüm seralarda taban gübrelemesi yapılmış ancak kullanılan gübre çeşitleri farklılık göstermektedir. Organik gübre olarak tüm seralarda küçükbaş hayvan gübresi kullanılmaktadır. En yaygın kullanılan kimyasal gübreler Azot, Fosfor ve Potasyum olmakla birlikte verilen kimyasal gübrelerin çeşitleri, dekara verilen miktarları ve verildikleri dönemler seralara göre farklılık göstermektedir. Gübreleme, damla veya yağmurlama sulama ile birlikte yapılmaktadır. Seraların yetiştirme alanları 5 ile 12 da arasında değişmektedir. Seraların yan yükseklikleri 5.5-9 m, çatı yükseklikleri 10-11 m arasında değişmektedir. Seralardaki sıra arası ve sıra üzeri dikim mesafeleri kısmı farklılıklar göstermektedir. Toprak yapısı, 1 no'lu serada kumlu tınlı, öteki seralarda killi tınlı olarak bildirilmiştir.

\section{Yöntem}

Deneme alanındaki seralarda yürütülen çalışmada, materyal olarak seçilen "Grand Nain" çeşidinden homojen 5 bitki belirlenmiştir. İncelenen özellikler, her yinelemede 1 bitki olmak üzere 5 tekerrürlü olarak belirlenen bu bitkilerde değerlendirilmiştir. Bu bitkilerde bazı morfolojik (gövde çevresi, gövde kesit alanı), bazı verim bileşenleri (hevenk uzunluğu, hevenk çevresi, hevenk çapı ve hevenk ağırlığı, tarak sayısı, tarak ağırlığı, parmak sayısı ve gövde kesit alanına düşen verim) ve pomolojik özelliklere ait kriterler (parmak ağırlığı, parmak uzunluğu ve çevresi, meyve kabuk kalınlığı, meyve kabuk ağırlığı, meyve eti oranı, SÇKM ve titre edilebilir asit) incelenmiştir.

Farklı dönemlerde hasat olumuna gelen hevenkler kesilip tartımları yapılmış ve ortalama hevenk ağırlıkları hesaplanmıştır. Hevenklerin derimi, parmaklardaki köşeliliğin dörtte üçü kaybolduğu dönemde ( $3 / 4$ dolulukta) yapılmıştır. Derimi yapılan hevenklere 24 saat süreyle 1000 ppm etilen gazı uygulanmıştır (Paydaş ve Pekmezci, 1983). Olgunlaştırma, $18^{\circ} \mathrm{C}^{\prime}$ de $\% 80-85$ oransal nemde gerçekleştirilmiştir. Olgunlaştırmadan sonra tam yeme olumunda bu hevenklerden pomolojik ve morfolojik analizlerin gerçekleştirilmesi amacıyla meyve örnekleri alınmıştır. Daha sonra Mustafa Kemal Üniversitesi Ziraat Fakültesi Bahçe Bitkileri Bölümüne ait pomoloji laboratuvarında kalite analizleri yapılmıştır.

\section{Bitki özellikleri}

Seçilen bitkilerin gövde çevresi $(\mathrm{cm})$, toprak yüzeyinin $20 \mathrm{~cm}$ üzerinden şerit metre ile ölçülmüştür. Gövde kesit alanı $\left(\mathrm{cm}^{2}\right)$ gövde çevresinden hesaplanan yarıçap yardımıyla belirlenmiştir. 
Hevenk özellikleri

Her serada 5'er adet homojen bitki belirlenerek bu bitkilerin hevenk ağırlıkları terazide tartılarak bulunmuştur. Ayrıca, hevenk uzunluğu $(\mathrm{cm})$, hevengin sap kısmı ile en uçtaki meyve arası olarak; hevenk çevresi $(\mathrm{cm})$ ise, hevengin orta kısmından şerit metre ile ölçülmüştür. Hevenk çapı, ölçülen hevenk çevresinden yararlanarak Ç=Rx3.14 denklemi kullanılarak hesaplanmıştır. Tarak sayısı, her bir hevenkte bulunan tarak sayısı; parmak sayısı, her hevenkte belirlenen parmak sayısı olarak hesaplanmıştır. Tarak ağırlığı, her hevenkte bulunan tarakların tek tek terazide tartılmasıyla elde edilen değerlerin toplamının tarak sayısına bölünmesiyle ortalama olarak hesaplanmıştır.

\section{Kalite özellikleri}

Parmak Ağırlıkları (g): Bu değer, yeme olumundaki parmakların 0.5 grama hassas terazide tek tek tartılmasıyla belirlenmiştir.

\section{Parmakların En $(\mathrm{mm})$ ve Boy $(\mathrm{cm})$ Ölçümleri}

Parmakların enleri, tam orta kısmından kumpas yardımıyla ölçülerek belirlenmiştir. Parmakların boyları ise parmakların boyuna en dış kısmından bir şerit metre yardımıyla ölçülmüştür.

\section{Meyve kabuk ağırlığı ve Kabuk kalınlığı}

Kabuk ağırlığı, yeme olumundaki meyvelerin kabuklarının soyulup hassas terazide tartılmasıyla belirlenmiştir. Bu meyvelerin kabuk kalınlıkları ise dijital kumpas ile ölçülerek belirlenmiştir.

\section{Meyve eti oranı (\%)}

Yeme olumundaki meyvelerde aşağıdaki formüle göre hesaplanmıştır.

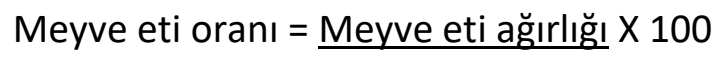 Meyve (Parmak) ağırlığı}

\section{Suda Çözünebilir Toplam Kuru Madde (SÇKM \%)}

Yeme olumundaki meyvelerin kabukları soyularak, katı meyve sıkacağında sıkılmış ve çıkan püreden alınan örnek dijital refraktometre ile ölçülerek belirlenmiştir.
Titre edilebilir asitlik (TEA, \%)

Meyvelerden 50 gram alınarak bunun 5 katı $250 \mathrm{ml}$ saf su ile birlikte blenderden geçirilmiş ve filtre edilen örnekten $10 \mathrm{ml}$ alınarak 0.1 normal $\mathrm{NaOH}$ ile dijital büret yardımıyla $\mathrm{pH}$ 8.1'e gelene kadar titre edilmiştir. Bir örnekteki titre edilebilir $\%$ asit miktarı malik asit cinsinden g malik asit/100 g olarak aşağıdaki formülle hesaplanmıştır (Cemeroğlu, 2010).

$$
\text { (V) } \times(f) \times(E)
$$

Titrasyon Asitliği \% = ---------------- $\times 100$

M

$\mathrm{V}$ : Harcanan $\mathrm{NaOH}$ miktarı, $\mathrm{mL}$

f : 0.1 N Baz Çözeltisinin Faktörü

E : $1 \mathrm{~mL} 0.1 \mathrm{~N} \mathrm{NaOH}$ 'in Eşdeğeri Asit Miktarı, g

$M$ : Titre Edilen Örneğin Gerçek Miktarı, mL veya $\mathrm{g}$

\section{Verim özellikleri}

Gövde kesit alanına düşen verim $\left(\mathrm{g} \mathrm{cm}^{-2}\right)$ :Her bir bitki için hevenk ağırlığınıngövde kesit alanına bölünmesiyle belirlenmiştir.

\section{Dekara verim}

Her bir serada dekardaki bitki sayısı 166 olarak dikkate alınmış ve çeşidin kendine özgü ortalama hevenk ağırlığı ile çarpılarak hesaplanmıştır.

İstatistiksel analizler

Denemeden elde edilen verilerde, COSTAT bilgisayar paket programında tesadüf blokları deneme desenine göre varyans analizi yapılmış ve ortalamalar arasındaki farklar Tukey testi ile karşılaştırılmıştır.

\section{Araştırma Bulguları ve Tartışma}

\section{Bitki özellikleri}

İncelenen özelliklerden bitki gövde çevresi ve gövde kesit alanı bakımından en yüksek değerler(sırasıyla $95.0 \mathrm{~cm}, 719.38 \mathrm{~cm}^{2}$ ) 4 no'lu seradaki bitkilerde, en düşük değerler(sırasıyla $65.0 \mathrm{~cm}$ ve $349.51 \mathrm{~cm}^{2}$ ) ise 3 no'lu seradaki bitkilerde belirlenmiştir. Her iki özellik açısından, seralar arasındaki bu farklılık istatistiksel bakımdan da önemli bulunmuştur(Çizelge 2). 
Grand Nain muz çeşidinde yapılan bazı çalışmalarda, gövde çevresi 58.54 ile $90,70 \mathrm{~cm}$ arasında ölçülmüştür (Gübbük ve ark., 2004; Baysal, 2011; Navaneethakrishnan ve ark., 2013). Dwarf Cavendish muz çeşidinde yapılan bazı çalışmalarda (Kalay, 2014; Balkıç ve ark., 2018) gövde çevresi 70.66-78.80 cm değerleri arasındaki bulunmuştur.

Çalışmamızda belirlenen gövde çevresine ilişkin bulgular (65.0-95.0 cm), literatürdeki bu bulgularla uyumlu bulunmaktadır.

\section{Hevenk özellikleri}

Farklı lokasyonlarda yetiştirilen Grand Nain muz çeşidinde belirlenen hevenk özellikleri ile verim bileşenlerine ait veriler Çizelge 3 'te verilmiştir.

Çizelge 2. Arsuz'da yetiştirilen Grand Nain muz çeşidinin bitki gövde çevresi ve gövde kesit alanı

Table 2. Pseudostem circumference and pseudostem section area of 'Grand Nain' banana cultivar grown in Arsuz

\begin{tabular}{|c|c|c|}
\hline $\begin{array}{l}\text { Lokasyon/Sera } \\
\text { Location/Greenhouse }\end{array}$ & $\begin{array}{c}\text { Bitki gövde çevresi }(\mathrm{cm}) \\
\text { Pseudostem circumference }\end{array}$ & $\begin{array}{c}\text { Gövde kesit alanı }\left(\mathrm{cm}^{2}\right) \\
\text { Pseudostem section }\end{array}$ \\
\hline 1 & $80.8 \mathrm{~b}$ & $526.28 \mathrm{ab}$ \\
\hline 2 & $70.8 \mathrm{~cd}$ & $400.48 \mathrm{~b}$ \\
\hline 3 & $65.0 \mathrm{~d}$ & $349.50 \mathrm{~b}$ \\
\hline 4 & $95.0 \mathrm{a}$ & $719.38 \mathrm{a}$ \\
\hline 5 & $78.6 \mathrm{bc}$ & $493.74 \mathrm{~b}$ \\
\hline Önemlilik-Significance & $\mathrm{HSD} \% 1: 8.86$ & HSD $\% 5: 198.26$ \\
\hline
\end{tabular}

\section{Hevenk ağırlığı}

Incelenen seralarda, hevenk ağırlığı bakımından en yüksek değer(47.0 kg) 4 no'lu seradan, en düşük değer(30.8 kg) 3 no'lu seradan elde edilmiştir. Seralar arasındaki bu farklılık, istatistiksel olarak \% 1 düzeyinde önemli bulunmuştur.

\section{Hevenk çevresi ve hevenk uzunluğu}

Hevenk çevresi ve uzunluğu bakımından da en yüksek değerler (sırasıyla $129.0 \mathrm{~cm}$ ve $113.8 \mathrm{~cm}$ ) 4 no'lu serada belirlenirken; en düşük hevenk çevresi $(118.2 \mathrm{~cm}) 5$ no'lu serada, en düşük hevenk uzunluğu $(90.4 \mathrm{~cm})$ ise 3 no'lu serada belirlenmiştir. Seralar arasındaki bu farklııı, her iki özellik bakımından da istatistiksel olarak \%1 düzeyinde önemli bulunmuştur.

\section{Tarak sayısı ve tarak ağırlığı}

İncelenen seralarda en yüksek tarak sayısı 13.8 adet ile 4 no'lu serada belirlenirken, en düşük değer 12.4 adet ile 5 no'lu serada belirlenmiştir. Tarak ağırlığı bakımından ise en yüksek değer (1481.96 g) 3 no'lu serada, en düşük değer (1286.36 g) 5 no'lu serada tespit edilmiştir. Seralar arasındaki farklıık, tarak sayısı bakımından istatistiksel olarak önemli bulunmazken, tarak ağırlığı bakımından \% 1 düzeyinde önemli bulunmuştur.

Çizelge 3. Arsuz'da yetiştirilen Grand Nain muz çeşidinin hevenk özellikleri

Table 3. Bunch parameters of 'Grand Nain' banana cultivar grown in Arsuz

\begin{tabular}{|c|c|c|c|c|c|c|}
\hline $\begin{array}{c}\text { Lokasyon/ } \\
\text { Sera } \\
\text { Location/ } \\
\text { Greenhouse }\end{array}$ & $\begin{array}{l}\text { Hevenk ağırlığı } \\
\text { (kg) } \\
\text { Bunch weight }\end{array}$ & $\begin{array}{l}\text { Hevenk çevresi } \\
(\mathrm{cm}) \\
\text { Bunch } \\
\text { circumference }\end{array}$ & $\begin{array}{c}\text { Hevenk } \\
\text { uzunluğu } \\
\text { (cm) } \\
\text { Bunch lenght }\end{array}$ & $\begin{array}{l}\text { Tarak sayısı } \\
\text { (adet) } \\
\text { Number of } \\
\text { hands }\end{array}$ & $\begin{array}{l}\text { Tarak ağırlığı } \\
\text { (g) } \\
\text { Hands weight }\end{array}$ & $\begin{array}{c}\text { Parmak } \\
\text { sayısı(adet) } \\
\text { Number of } \\
\text { fingers }\end{array}$ \\
\hline 1 & $41.0 \mathrm{ab}$ & $127.6 \mathrm{ab}$ & $101.6 \mathrm{ab}$ & 12.8 & $1356.24 \mathrm{ab}$ & $261.8 \mathrm{ab}$ \\
\hline 2 & $40.4 \mathrm{ab}$ & $124.0 \mathrm{ab}$ & $93.4 \mathrm{~b}$ & 12.8 & $1453.32 \mathrm{a}$ & $242.4 \mathrm{abc}$ \\
\hline 3 & $30.8 c$ & $125.6 \mathrm{ab}$ & $90.4 b$ & 12.4 & $1481.96 \mathrm{a}$ & $198.6 \mathrm{c}$ \\
\hline 4 & $47.0 \mathrm{a}$ & $129.0 \mathrm{a}$ & $113.8 \mathrm{a}$ & 13.8 & $1291.54 \mathrm{~b}$ & $289.6 \mathrm{a}$ \\
\hline 5 & $33.2 \mathrm{bc}$ & $118.2 \mathrm{~b}$ & $92.6 \mathrm{~b}$ & 12.4 & $1286.36 \mathrm{~b}$ & 230.4 bc \\
\hline $\begin{array}{l}\text { Önemlilik } \\
\text { Significance }\end{array}$ & HSD\%1:8.18 & HSD\%1:9.91 & HSD\%1:15.24 & ÖD. & HSD\%1:148.72 & $\mathrm{HSD}_{\% 1}: 52.62$ \\
\hline
\end{tabular}




\section{Parmak sayısı}

Ortalama parmak sayısı bakımından en yüksek değer (289.6 adet) 4 no'lu seradan, en düşük değer ise 3 no'lu seradan (198.6 adet) elde edilmiştir. Seralar arasındaki bu farklılık, istatistiksel olarak \%1 düzeyinde önemli bulunmuştur.

Çalışmamızda, hevenk ağırlığı 30.8-47.0 kg; hevenk çevresi $118.2-129.0 \mathrm{~cm}$ ve hevenk uzunluğu 90.4-113.8 cm olarak belirlenmiştir. Lokasyonlar arasındaki bu faklılık, her üç özellik bakımından da istatistiksel olarak \%1 düzeyinde önemli bulunmuştur. Araştırmamızda, tarak sayısı 12.4-13.8 adet, tarak ağırlığı 1286.36-1481.96 g, parmak sayısı 198.6-289.6 adet olarak tespit edilmiştir. Lokasyonlar arasındaki farklılık, tarak sayısı bakımından istatistiksel olarak önemli bulunmazken, tarak ağırlığı ve parmak sayısı bakımından \% 1 düzeyinde önemli bulunmuştur.

Gübbük ve ark. (2004)'nın yaptığı bir çalışmada, Grand Nain'de hevenk ağırlığı 26.7$34.8 \mathrm{~kg}$; tarak sayısı 11.9-13.6 adet ve parmak sayısı 200.2-243.4 adet olarak belirlenmiştir. Kenya'da yapılan bir çalışmada, hevenk ağırlığının 14.2-41.4 kg arasında değiştiği belirlenmiştir (Njuguna ve ark., 2008). Gervacio ve ark.(2008), 27 değişik muz klonunda hevenk ağırlıklarını 6,3 kg (Rose) ile 46.1 kg (FHIA-17) arasında belirlemişlerdir. Bu değerler, araştırmamız da belirlenen değerlerden daha düşüktür. Adebayo ve ark.(2009), Nijerya'da yaptıkları çalışmada hevenk ağırlığını 8.5-19.2 kg; tarak sayısını 6-18 adet ve toplam parmak sayısını ise 83-296 adet arasında belirlemişlerdir.Güven (2011), hevenk ağırlığını $57.42-41.78 \mathrm{~kg}$, tarak sayısını 10.6713.33 adet; parmak sayısını 224.76-257.57 adet arasında belirlemiştir.

Baysal'ın (2011) yaptığı bir çalışmada, Grand Nain'in hevenk ağırlığı 36.4 kg, hevenk uzunluğu 125.2, hevenk genişliği $45.58 \mathrm{~cm}$ olarak ölçülmüştür. Aynı araştırmada, Grand Nain muz klonunun tarak sayısı, 12.35; taraktaki parmak sayısı, 25, toplam parmak sayısı ise 303.12 adet olarak belirlenmiştir. Navaneethakrishnan ve ark. (2013), Hindistan'da Grand Nain'in hevenk ağırlığını 18.11-15.37 kg, tarak sayısını 7.08-10.61 adet, tarak ağırlığını 2.20-1.64 kg arasında belirlemiştir.

Sarıdaş ve ark. (2017)'nın yaptıkları çalışmada, Hassa'daki ortalama hevenk ağırlığı (71.3 kg), Anamur'a (55.8 kg) göre önemli düzeyde yüksek bulunmuştur. Erdemli'de yapılan bir çalışmada ise hevenk ağırlığı 38.00-50.32 g, tarak sayısı 11.4012.40 adet, tarak ağırlığı $3.10-4.00 \mathrm{~kg}$ ve hevenkteki parmak sayısı 208.80-237.40 adet, değerleri arasında bulunmuştur (Kalay, 2014).

Çalışmamızda belirlenen hevenk ağırlıkları, daha önce yapılan birçok çalışmada (Gübbük ve ark., 2004; Njuguna ve ark., 2008; Gervacio ve ark., 2008; Adebayo ve ark., 2009; Baysal, 2011; Navaneethakrishnan ve ark., 2013; Balkıç ve ark., 2017 ve 2018) belirlenen değerlerden daha yüksek, Sarıdaş ve ark. (2017)'nın bulgularından daha düşük, Kalay'ın (2014) bulgularına benzer bulunmuştur. Çalışmamızda belirlenen hevenkteki ortalama tarak ve parmak sayılarıbakımından da öncekiçalışmalardabelirlenendeğerlerden daha yüksek değerler elde edilmiştir.

\section{Kalite özellikleri}

Farklı lokasyonlarda yetiştirilen Grand Nain muz çeşidinde belirlenen bazı meyve kalite özelliklerine ait veriler Çizelge 4'de verilmiştir.

\section{Parmak Ağırı̆̆ı (g):}

İncelenen seralarda parmak ağırlığı bakımından en yüksek değer (148.02 g) 3 no'lu seradan, en düşük değer (126.16 g) 4 no'lu seradan elde edilmiştir. Seralar arasındaki farklılık istatistiksel olarak \% 1 düzeyinde önemli bulunmuştur.

\section{Parmakların en $(\mathrm{mm})$ ve boy $(\mathrm{cm})$ ölçümleri}

En yüksek parmak en ve boy değerleri (sırasıyla, $40.51 \mathrm{~mm}$ ve $26.42 \mathrm{~cm}$ ) 4 no'lu seradan, en düşük değerler ise (sırasıyla $39.68 \mathrm{~mm}$ ve 21.43 cm) 5 no'lu seradan elde edilmiştir.

Parmak boyu bakımından seralar arasındaki farklılık istatistiksel olarak \%1 düzeyinde önemli çıkarken, parmak eni bakımından farklılık önemli bulunmamıştır. 
Suda çözünebilir kuru madde (\%) ve titre edilebilir asitlik (\%)

En yüksek suda çözünebilir kuru madde oranı (\%18.48) 2 no'lu seradaki meyvelerden, en düşük oran (\% 16.64) ise 5 no'lu seradaki meyvelerden elde edilmiştir. Seralar arasındaki bu farklılık istatistiksel bakımdan \% 5 düzeyinde önemli bulunmuştur. Çalışmada meyvelerin titre edilebilir asitlikleri \% 0.29 ile \% 0.33 arasında belirlenmiştir. Asitlik bakımından seralar arasında önemli bir farklılık bulunmamıştır.
Meyve kabuk ağırlığı (g), kabuk kalınlığı(mm) ve meyve eti oranı (\%)

Denemede Grand Nain muz çeşidinden elde edilen meyve kabuk ağırlı̆̆ı, kabuk kalınlığı ve meyve eti oranları Çizelge 5 'te verilmiştir.

Gerek meyve kabuk ağırlığı ve meyve kabuk kalınlığı, gerek meyve eti oranı bakımından en yüksek değerler (sırasıyla, $44.24 \mathrm{~g}, 3.71 \mathrm{~mm}$ ve \% 69.47) 3 no'lu seradan elde edilirken; ilk iki özellik bakımından en düşük değerler (sırasıyla $40.24 \mathrm{~g}$ ve $3.41 \mathrm{~mm}$ ) 4 no'lu seradan, en düşük meyve oranı (\% 67.68) 5 no'lu seradan elde edilmiştir. Her üç özellik bakımından da seralar arasındaki farklılık, istatistiksel olarak önemli bulunmamıştır.

Çizelge 4. Arsuz'da yetiştirilen Grand Nain muz çeşidinin meyve kalite özellikleri

Table 4. Fruit quality parameters of 'Grand Nain' banana cultivar grown in Arsuz

\begin{tabular}{|c|c|c|c|c|c|}
\hline $\begin{array}{l}\text { Lokasyon/ } \\
\text { Sera } \\
\begin{array}{l}\text { Location/ } \\
\text { Greenhouse }\end{array}\end{array}$ & $\begin{array}{c}\text { Parmak ağırlığı } \\
(\mathrm{g})\end{array}$ & $\begin{array}{c}\text { Parmak eni } \\
(\mathrm{mm}) \\
\text { Finger weight }\end{array}$ & $\begin{array}{c}\text { Parmak boyu } \\
(\mathrm{cm}) \\
\text { Finger lenght }\end{array}$ & $\begin{array}{c}\text { SÇKM } \\
(\%) \\
\text { Solible solids } \\
\text { content }\end{array}$ & $\begin{array}{c}\text { Asitlik } \\
(\%) \\
\text { Acidity }\end{array}$ \\
\hline 1 & $134.72 \mathrm{ab}$ & 40.03 & $22.75 \mathrm{~b}$ & $18.40 \mathrm{a}$ & 0.31 \\
\hline 2 & $137.60 \mathrm{ab}$ & 40.26 & $22.13 \mathrm{~b}$ & $18.48 \mathrm{a}$ & 0.32 \\
\hline 3 & $148.02 \mathrm{a}$ & 40.51 & $22.72 \mathrm{~b}$ & $17.36 \mathrm{ab}$ & 0.29 \\
\hline 5 & $126.16 \mathrm{~b}$ & 40.06 & $26.42 \mathrm{a}$ & $17.94 \mathrm{ab}$ & 0.29 \\
\hline $\begin{array}{l}\text { Önemlilik } \\
\text { Significance }\end{array}$ & $131.50 \mathrm{ab}$ & 39.68 & $21.43 \mathrm{~b}$ & $16.64 \mathrm{~b}$ & 0.33 \\
\hline
\end{tabular}

Çalışmamızda, parmak en ve boy değerleri ile parmak ağırlıkları sırasıyla 39.68-40.51 mm ve 21.43-26.42 cm ile 126.16-148.02 g arasında ölçülmüştür.

Meyve kabuk ağırlığı, meyve kabuk kalınlığı ve meyve eti oranı değerleri sırasıyla, 40.24-44.24 g ve 3.41-3.71 $\mathrm{mm}$ ve \% 67.69-69.47 arasında belirlenmiştir. Suda çözünebilir kuru madde oranı
\% 16.64-18.48, asitlik ise \% 0.25-0.28 arasında elde edilmiştir.

Gübbük ve ark. (2004) Grand Nain'de parmak çevresini açıkta $12.0 \mathrm{~cm}$, örtü altında $12.7 \mathrm{~cm}$; parmak uzunluğunu açıkta $22.2 \mathrm{~cm}$, örtü altında $21.4 \mathrm{~cm}$ olarak belirlemişlerdir. Gervacio ve ark.(2008), muz klonlarında parmak uzunluklarını $8.8-25.8 \mathrm{~cm}$ arasında belirlemişlerdir.

Çizelge 5. Arsuz'da yetiştirilen Grand Nain muz çeşidinin meyve kalite özellikleri

Table 5. Fruit quality parameters of 'Grand Nain' banana cultivar grown in Arsuz

\begin{tabular}{|c|c|c|c|}
\hline $\begin{array}{l}\text { Lokasyon/Sera } \\
\text { Location/Greenhouse }\end{array}$ & $\begin{array}{c}\text { Meyve kabuk ağılığı (g) } \\
\text { Fruit peel weight }\end{array}$ & $\begin{array}{c}\text { Meyve kabuk kalınlığı (g) } \\
\text { Fruit peel thickness }\end{array}$ & $\begin{array}{c}\text { Meyve Eti Oranı (\%) } \\
\text { Peel/pulp ratio }\end{array}$ \\
\hline 1 & 42.36 & 3.62 & 68.87 \\
\hline 2 & 42.28 & 3.68 & 69.40 \\
\hline 3 & 44.24 & 3.71 & 69.47 \\
\hline 4 & 40.24 & 3.41 & 68.14 \\
\hline 5 & 42.24 & 3.63 & 67.68 \\
\hline $\begin{array}{l}\text { Önemlilik } \\
\text { Significance }\end{array}$ & ÖD & ÖD & ÖD \\
\hline
\end{tabular}


Güven'in (2011) çalışmasında, parmak ağırlığı $172.36-127.91 \mathrm{~g}$, parmak çevresi $13.66-11.00 \mathrm{~cm}$, parmak uzunluğu $24.58-21.00 \mathrm{~cm}$ arasında saptanmıştır. Kalite kriterleri açısından önemli olan meyve kabuk ağırlığı 35.88-22.22 g, meyve kabuk kalınlığı $1.75-0.94 \mathrm{~mm}$ ve meyve eti oranı \% 84.89-81.43 arasında belirlenmiştir. Incelenen diğer kalite kriterlerinden suda çözünebilir kuru madde miktarı \% 19.62-16.09 arasında kaydedilmiştir.

Kaliteyi belirleyen önemli parametreler arasında yer alan ve dış görünüşü çok etkileyen meyve boyutu ve ağırlığı, Hatay'ın Hassa ilçesinde yetiştirilen bitkilerden alınan meyvelerde, Anamur'daki meyvelerden daha yüksek bulunmuştur. Hassa'da meyve en değeri $37.5 \mathrm{~mm}$, boy değeri $22.3 \mathrm{~cm}$ olarak belirlenirken, Anamur'da sırasıyla $29.4 \mathrm{~mm}$ ve $17.5 \mathrm{~cm}$ olarak ölçülmüştür (Sarıdaş ve ark., 2017). Balkıç ve ark. (2017 ve 2018)'nın Dwarf Cavendish muz çeşidinde yaptıkları çalışmalarda, parmak ağırlığı $71.00-122.80 \mathrm{~g}$, parmak çevresi $10.28-12.28 \mathrm{~cm}$ ve parmak uzunluğu ise $20.67-23.03 \mathrm{~cm}$ arasında saptanmıştır. Çalışmada, kabuk kalınlığı 2.71-3.19 $\mathrm{mm}$, meyve et oranı \% 67.17-65.01; SÇKM \% 18.40-22.86 olarak ölçülmüştür. Baysal'ın (2011) yaptığı bir çalışmada Grand Nain'de parmak ağırlığı 114.15 g; parmak uzunluğu $19.54 \mathrm{~cm}$, parmak çevresi, $10.79 \mathrm{~cm}$, kabuk kalınlığı ise 2.39 $\mathrm{mm}$ olarak belirlenmiştir. Gübbük ve ark. (2004), farklı çeşitleri kıyasladıkları bir çalışmada, parmak uzunluklarını 18.9 - $22.9 \mathrm{~cm}$ olarak ölçmüştür. Kalay’ın (2014) yürüttüğü çalışmada, parmak ağırlığı 156.71-190.00 g, parmak çevresi 3.57-3.99 $\mathrm{cm}$ ve parmak uzunluğu 21.35-24.05 cm değerleri arasında bulunmuştur. Aynı çalışmada, kalite kriterleri içerisinde yer alan SÇKM değerleri olgun meyvelerde \% 21.33-24.70 olarak ölçülmüştür. Hassa bölgesinde yetiştirilen muzların SÇKM değerlerinin (\% 19.7), Anamur'a (\% 18.6) göre daha yüksek olduğu görülmüştür. Sarrwy ve ark. (2012), farklı dikim mesafelerinin meyve kalite özellikleri üzerine etkilerini inceledikleri çalışmalarında; en yüksek SÇKM içeriklerini \% 19.73-19.77 değerleri ile 3x4 m dikim sıklığından, en düşük değerleri ise \% 18.33-18.53 olarak 3x1 m olan dikim sıklığından elde etmişlerdir. Attia ve ark. (2009), ise farklı gübre uygulamaları sonucu SÇKM içeriklerinin \% 14.57-17.57 arasında değiştiğini bildirmişlerdir. Sarıdaş ve ark. (2017) yaptıkları çalışmada, SÇKM üzerine farklı bölgelerin etkisi istatistiksel olarak önemsiz bulunmasına karşın, Hassa koşullarında yetiştirilen muzların daha yüksek SÇKM değerine sahip olduklarını belirtmiştir. Çalışmamızda bazı meyve kalite özelliklerine (parmak çevresi, parmak uzunluğu, meyve kabuk kalınlığı ve meyve kabuk ağırlığı) ait bulgular, Gübbük ve ark. (2004), Baysal (2011), Güven (2011), Kolay (2011), Sarıdaş ve ark. (2017), Balkıç ve ark. (2017 ve 2018) belirledikleri değerlerden daha yüksek bulunmuştur. Parmak ağırlığına ait bulgularımız ise Kalay (2014) ile Sarıdaş ve ark. (2017)'nın bulgularından daha düşük, Baysal (2011) ve Balkıç'ın (2018) bulgularından daha yüksek bulunmuştur. İncelenen diğer kalite kriterlerinden biri olan suda çözünebilir kuru madde miktarı değerlerimiz ise öteki çalışmaların bulgularından daha düşük bulunmaktadır.

\section{Verim özellikleri}

Grand Nain muz çeşidinde belirlenen verime ilişkin bulgular Çizelge $6^{\prime}$ da verilmiştir.

Çizelge 6. Arsuz' da yetiştirilen Grand Nain muz çeşidinin verimi Table 6. Yield of 'Grand Nain' Banana cultivar grown in Arsuz

\begin{tabular}{|c|c|c|}
\hline $\begin{array}{l}\text { Lokasyon/Sera } \\
\text { Location/ } \\
\text { Greenhouse }\end{array}$ & $\begin{array}{l}\text { Birim gövde kesit alanına düşen verim (g } \\
\mathrm{cm}^{-2} \text { ) } \\
\text { Yield per pseudostem section }\end{array}$ & $\begin{array}{l}\text { Dekara verim } \\
(\mathrm{kg}) \\
\text { Yield per decare }\end{array}$ \\
\hline 1 & $77.54 \mathrm{c}$ & $6806.0 \mathrm{~b}$ \\
\hline 2 & $100.87 \mathrm{a}$ & $6706.4 \mathrm{~b}$ \\
\hline 3 & $93.46 \mathrm{~b}$ & $5112.8 c$ \\
\hline 4 & $65.54 \mathrm{~d}$ & $7802.0 \mathrm{a}$ \\
\hline 5 & $65.35 \mathrm{~d}$ & $5511.2 \mathrm{c}$ \\
\hline $\begin{array}{l}\text { Önemlilik } \\
\text { Significance }\end{array}$ & HSD\%1: 6.36 & HSD\%1: 708.38 \\
\hline
\end{tabular}


Gövde kesit alanına düşen verim $\left(\mathrm{g} \mathrm{cm}^{-2}\right)$

Çalışmamızda, birim gövde kesit alanına düşen verim bakımından en yüksek değer $\left(107.87 \mathrm{~g} \mathrm{~cm}^{-2}\right)$, 2 no'lu seradaki bitkilerden alınmış ve bunu 3 no'lu sera (93.46 $\mathrm{g} \mathrm{cm}^{-2}$ ) izlemiştir. En düşük değer ise 5 no'lu seradan (65.35 $\mathrm{g} \mathrm{cm}^{-2}$ ) alınmıştır. Seralar arasındaki bu farklılık, istatistiksel olarak \% 1 düzeyinde önemli bulunmuştur.

\section{Dekara verim}

Dekara verim bakımından en yüksek değer (7802 kg), 4 no'lu seradan alınmış ve bunu 6806 kg ile 1 no'lu sera izlemiştir. En düşük verim değeri ise 3 no'lu seradan (5112.8 kg) alınmıştır. Verim bakımından seralar arasındaki bu farklılık istatistiksel olarak da \% 1 düzeyinde önemli bulunmuştur.

Güven'in (2011) yaptığı bir çalışmada, verim bileşenleri (gövde kesit alanına düşen verim ve hektara verim ) çeşit ve klonlara göre farklılık göstermiştir. Çalışmada, gövde kesit alanına düşen verim $525.00 \mathrm{gcm}^{-2}$ ile $336.67 \mathrm{~g} \mathrm{~cm}^{-2}$, hektara verim 86.08 ton/ha-62.69 ton/ha arasında kaydedilmiştir. Balkıç ve ark. (2018)'nın, Dwarf Cavendish muz çeşidinde yaptıkları bir çalışmada, gövde kesit alanına düşen verim 22.01$55.98\left(\mathrm{~g} \mathrm{~cm}^{-2}\right)$, hektara verim 14.1-37.6 ton olarak belirlenmiştir.

Çalışmamızın verim değerleri, Güven (2011)'in bulgularından düşük ancak, Balkıç ve ark. (2018)'nın bulgularından daha yüksek bulunmuştur.

\section{Sonuç}

Muzda morfolojik özellikler, gerek çeşit ve gerek yetiştirme sisteminden etkilenmektedir. Bu konuda farklı araştırıcılar tarafından yapılan çalışmalarda, morfolojik özelliklerin çeşitler yanında, yetiştirme sistemlerinden etkilendiği bildirilmiştir (Galán Saúco ve ark., 1995; Mendez Hernandez 1998; Eckstein ve ark., 1998; Galán Saúco ve ark., 2000; Gübbük ve ark., 2004). Nitekim, çalışmamızda da elde edilen sonuçların gerek çeşit gerek yetiştirme sistemlerinin etkisi ile önceki çalışmalardan farklı ve benzer yanları değerlendirilmiştir.
Çalışmamızda, incelenen özelliklerden bitki gövde çevresi $65.0-95.0 \mathrm{~cm}$ ve gövde kesit alanı 349.51-719.38 cm² olarak belirlenmiştir. Hevenk ağırlığı 30.8-47.0 kg; hevenk çevresi 118.2-129.0 $\mathrm{cm}$ ve hevenk uzunluğu 90.4-113.8 cm olarak belirlenmiştir. Lokasyonlar arasındaki bu farklılık, her üç özellik bakımından da istatistiksel olarak \%1 düzeyinde önemli bulunmuştur. Araştırmamızda, tarak sayısı 12.4-13.8 adet, tarak ağırlığı 1286.36-1481.96 g, parmak sayısı 198.6289.6 adet olarak tespit edilmiştir. Tarak sayısı bakımından lokasyonlar arasındaki farklılık istatistiksel bakımdan önemli bulunmazken, tarak ağırlığı ve parmak sayısı bakımından lokasyonlar arasındaki farklılık \% 1 düzeyinde önemli bulunmuştur. Çalışmamızda, parmak en ve boy değerleri ile parmak ağırıkları sırasıyla 39.68$40.51 \mathrm{~mm}$ ve $21.43-26.42 \mathrm{~cm}$ ile $126.16-148.02 \mathrm{~g}$ arasında ölçülmüştür. Parmak ağırlığı ve parmak boyu bakımından lokasyonlar arasındaki farklılık istatistiksel olarak \%1 düzeyinde önemli çıkarken, parmak eni bakımından farklılık önemli bulunmamıştır. Araştırmamızda, meyve kabuk ağırlığı, meyve kabuk kalınlığı ve meyve eti oranı değerleri sırasıyla, 40.24-44.24 g ve 3.41-3.71 mm ve \% 67.6969 .47 arasında belirlenmiştir. Her üç özellik bakımından da lokasyonlar arasındaki farklılık, istatistiksel olarak önemli bulunmamıştır. Çalışmamızda, suda çözünebilir kuru madde oranı \% 16.64-18.48, asitlik ise \% 0.29-0.33 arasında elde edilmiştir. SÇKM bakımından lokasyonlar arasındaki farklılık istatistiksel bakımdan \% 5 düzeyinde önemli bulunurken, asitlik önemsiz çıkmıştır. Çalışmamızda, birim gövde kesit alanına düşen verim ve dekara verim sırasıyla 67.68-69.42 $\mathrm{g} \mathrm{cm}^{-2}$ ve $5112.8-7802 \mathrm{~kg}$ arasında bulunmuştur. Her iki özellik bakımından da lokasyonlar arasındaki farklılık istatistiksel olarak \% 1 düzeyinde önemli bulunmuştur.

Bu çalışmanın sonuçları, muz yetiştiriciliğinde yeni bir alan olan Arsuz ilçesi için fikir vermesi bakımından önemli olup, veriler, bu bölgenin ülkemiz muz yetiştiriciliği açısından ümitvar bir alan olabileceğini göstermektedir. Bu da muz ithalatının azaltılmasına katkı sağlayacak bir durumdur. 


\section{Kaynaklar}

Adebayo, A. T., Samuel, B. I., and Abdou, T. (2009). Evaluation of fruit and bunch traits in black sigatoka resistant plantain and banana hybrids. Journal of Tropical Agriculture, Food, Environment and Extension,8(2), 116-120.

Attia, M., Ahmed, M. A., and El-Sonbaty, M. R. (2009). Use of biotechnologies to increase growth, productivity and fruit quality of Maghrabi Banana under different rates of phosphorus. World Journal Agricultural Sciences, 5(2), 211-220.

Balkıç, R., Gübbük, H., ve Altınkaya, L.(2017). Muz hevenklerinde farklı tip ve renkte koruyucu torba uygulamalarının verim ve kalite üzerine etkileri.Adnan Menderes Üniversitesi Ziraat Dergisi, 14(1), 29-33.

Balkıç, R., Altınkaya, L., Gübbük, H., ve Tozlu, İ. (2018). Subtropik koşullarda muzlarda takipçi bitki seçimine yeni bir yaklaşım.Mediterranean Agricultural Sciences, 31(3), 193-197.

Barakat, M. R., El-Kosary, S., and Abd-El Nafea, M. H. (2011). Enhancing Williams banana cropping by using some organic fertilization treatments. Journal of Horticultural Science \& Ornamental Plants, 3(1), 29-37.

Baysal, F. (2011). Türkiye'de yetiştirilen bazı önemli muz klonlarında morfolojik ve moleküler karakterizasyon (Yayınlanmamış yüksek lisans tezi). Atatürk Üniversitesi Fen Bilimleri Enstitüsü Bahçe Bitkileri Anabilim Dalı, Erzurum, $75 \mathrm{~s}$.

Cemeroğlu, B. (2010). Gıda analizleri. Genişletilmiş 2. Baskı. Gıda Teknolojisi Derneği Yayınları, Ankara, 657 s.

Eckstein, K., Fraser, C., and Joubert, W. (1998). Greenhouse cultivation of banana in South Africa. Acta Horticulturae, 490, 135-147.

Galán Saúco, V., Cabrera Cabrera, J., and Hernandez Delgado, P. M. (1995). A comparison of banana cultivars 'Dwarf Cavendish', 'Grande Naine' and 'Williams', for the Canary Islands. Fruits, 50(4), 255266.

Galán Saúco, V., Cabrera Cabrera, J., Hernandez, D., and Pastor, R. (2000). Evaluation of medium-height cavendish banana cultivars under the subtropical conditions of the canary islands. Acta Horticulturae, 490, 247-259.

Gervacio, D. D., Dawi, N. M., Fabregar, E. G., Molina, A. B., and Bergh, I. B. (2008). Agronomic performance of selected local and introduced banana cultivars (Musa spp.) under commercial management practices in Davao, Philippines. Philippine Journal of Crop Science, 33(3), 71-81.

Gübbük, H., Pekmezci, M., and Erkan, M. (2004). Production potential of Cavendish Cultivars (Musa spp. AAA) under greenhouse and field conditions in subtropical areas of Turkey. Acta Agriculturae Scandinavica, Section B, Soil and Plant Science, 54(4), 249-253.
Gübbük, H., Pekmezci, M., Selli, S., Erkan, M., Kafkas, E., Pinar, H., and Güneş, E. (2010). Değişik lokasyonlarda açıkta ve örtüaltında yetiştirilen 'Dwarf Cavendish' muz çeşidinde verim, bazı kalite kriterleri ve aroma maddeleri ile meyvelerin derim sonrası özelliklerinin belirlenmesi üzerinde araştırmalar. TÜBITAK, Proje No: 1070156. $247 \mathrm{~s}$.

Güven, D. (2011).Yeni bazı muz çeşit ve klonlarında fenolojik ve pomolojik özellikler ile bitki besin maddeleri ve hormonların dönemsel değişimlerinin belirlenmesi (Yayınlanmamış doktora tezi). Akdeniz Üniversitesi Fen Bilimleri Enstitüsü Bahçe Bitkileri Anabilim Dalı, Antalya, $210 \mathrm{~s}$.

Güven, D., ve Gübbük, H. (2018).Örtüaltında yetiştirilen bazı yeni muz çeşit/klonların fiziko-kimyasal özellikler açısından kıyaslanması.Bahçe,47(1), 11-16.

Kalay, N. (2014). Örtü altında yetiştirilen şimşek (Dwarf cavendishi L.)muz klonunda farklı gübre uygulamalarının meyve verim ve kalite kriterleri ile bitki besin elementlerinin alınımına etkilerinin belirlenmesi (Yayınlanmamış yüksek lisans tezi). Çukurova Üniversitesi, Fen Bilimleri Enstitüsü, Bahçe Bitkileri Anabilim Dalı, Adana, $99 \mathrm{~s}$.

Mendez Hernadez, C. (1998). A comparison of the parent crop of three cultivars of banana in the open air and under plastic mesh in the North of Tenerife. Acta Horticulturae, 490, 97-101.

Navaneethakrishnan, K. S., Gill, M. I. S., and Kumar, S. R. (2013). Effect of different levels of $N$ and $P$ on ratoon banana (Musa spp. AAA). Journal of Horticulture and Foresty, 5(6), 81-91.

Njuguna, J., Nguthi, F., Wepukhulu, S., Wambugu, F., Gitau, D., Karuoya, M., and Karamura, D. (2008). Introduction and evaluation of improved banana cultivars for agronomic and yield characteristics in Kenya. African Crop Science Journal, 16(1), 35-40.

Paydaş, S., ve Pekmezci, M. (1983). Muzların depolanması ve olgunlaştırılması üzerinde araştırmalar. Türkiye Bahçe Ürünlerinin Depolanması, Pazara Hazırlanması ve Taşınması Sempozyumu, içinde (306-321). Çukurova Üniversitesi, Adana.

Sarıdaş, M. A., Paydaş Kargı, S., Merve Bayıroğlu, B., ve Yağ, Ş. (2017). Türkiye muz yetiştiriciliği için yeni bir ekoloji.Yüzüncü Yıl Üniversitesi Tarım Bilimleri Dergisi, 27(3), 370-377.

Sarrwy, S., Mostafa, E. A. M., and Hassan, H. S. A. (2012). Growth, yield and fruit quality of Williams banana as affected by different planting distances. International Journal of Agricultural Research, 7(5), 266-275.

Stover, R. H., and Simmonds, N. W. (1987). Bananas. Third edition. Longman Group UK Ltd, 468 p.

TÜiK, (2019).Türkiye İstatistik Kurumu. Erişim adresi https://biruni.tuik.gov.tr/medas/?kn= 92 \& locale =tr. 